\title{
Prognostic Significance of DNMT3a Gene Expression and Reactive Nitrogen Species in Newly Diagnosed De- novo Adult Acute Myeloid Leukemia Patients
}

Inas A. Asfour, M.D1, Hany M. Hegab M.D1, Walaa A. El-Salakawy M.D1, Alia M. Saeed M.D1, Mohamed T. Hamza M.D2, and Dina A. Mansour, MSc1 1 Department of Internal Medicine, Clinical Hematology and Oncology Unit, Faculty of Medicine, Ain Shams University. 2 Department of Clinical pathology, Faculty of Medicine, Ain Shams University.

\begin{tabular}{|c|}
\hline Abstract \\
\hline $\begin{array}{l}\text { Objectives: DNA methylation is a major epigenetic } \\
\text { modifying mechanism for gene expression. There is } \\
\text { accumulating evidence in the literature about the critical } \\
\text { role of this mechanism in the process of carcinogenesis. } \\
\text { Also, the dichotomous nature of nitric oxide action } \\
\text { promoting or repressing cancers is increasingly realized. } \\
\text { There is a host of research work delineating the frequency } \\
\text { of DNMT3a mutation in AML, but little is known about its } \\
\text { level of expression or a probable relationship with } \\
\text { nitrosative stress. Aim: The primary aim is to assess } \\
\text { DNMT3a gene expression as well as nitric oxide levels in } \\
\text { newly diagnosed adult patients with denovo AML. The } \\
\text { secondary aim is to relate these two variables to other } \\
\text { disease features and prognostic indicators as well as } \\
\text { treatment outcomes. Methods: The study included } 45 \text { adult } \\
\text { denovo AML patients and 10 healthy control subjects. } \\
\text { Measurement of DNMT3a mRNA transcripts was done by } \\
\text { RT-PCR followed by Sanger sequencing of the gene for } \\
\text { R882 mutation. This was followed by the assessment of } \\
\text { serum nitrite level. Results: DNMT3a gene expression as } \\
\text { well as serum nitrite levels were significantly higher } \\
\text { amongst AML cases in relation to controls before } \\
\text { chemotherapy with P-values of <0.001 and } 0.035 \\
\text { respectively. Dividing patients into low and high expressors } \\
\text { in relation to the hotspot mutation demonstrated no } \\
\text { difference between the two groups in terms of } \\
\text { demographic, clinical and laboratory characteristics as well } \\
\text { as treatment outcomes. } \\
\text { Background }\end{array}$ \\
\hline
\end{tabular}

AML is a disease with marked molecular as well as . clinical diversity[1]. DNA methylation and histone tail modifications are the two fundamental epigenetic regulatory mechanisms that modulate gene expression. The process of DNA methylation is catalyzed by a set of enzymes called DNA methyl-transferases (DNMTs) [2]. DNMT3a is one of the frequently mutated genes in myeloid malignancies [3]. The R882 mutation is considered to be the most commonly encountered mutation[4]. Reactive nitrogen species (RNS) is a collective term that includes nitric oxide radical (NO•), peroxynitrite (ONOO-), nitrogen dioxide radical (NO2). The role of nitric oxide in tumorigenesis is controversial with bimodal action [5]

\section{Objective}

To assess DNMT3a gene expression as well as nitric oxide levels in newly diagnosed adult patients with denovo AML.

To relate these two variables to other disease features and prognostic indicators as well as treatment outcomes

\section{Patients and Methods}

\section{Patients:}

A Total number of 55 adult subjects were enrolled; 40 denovo adult AML cases (Group I) and 10 heathy age and sexmatched subjects (Group II). They were

recruited from the Clinical Hematology and Group I exhibited higher nitrite levels before Oncology Unit, Internal Medicine Group exhibited higher nitrite levels before

Oncology Unit, Internal Medicine chemotherapy than group II as well as than
Department at Ain Shams University themselves after receiving chemotherapy with PHospitals, Cairo, Egypt.

\section{Inclusion criteria}

-Adult patients $\geq 18$ yrs

2-Newly diagnosed AML patients.

3-Patients fit for intensive chemotherapy Exclusion criteria:

-Secondary acute leukemia. 2-MPAL.

3-Relapsed Acute Leukemia.

4-Patients who were considered unfit to intensive chemotherapy of curative intent Methods:

Measurement of DNMT3a mRNA transcripts was done by RT-PCR followed by Sanger sequencing to identify the presence or absence of DNMT3a R882 mutation. DNMT3a transcript levels were assayed twice; at diagnosis and on day 28.

Assessment of serum nitrite level as surrogate marker for $\mathrm{NO}$ using colorimetric methods was done. This was performed at diagnosis and on day 28

Statistical methodology: Data were analyzed using IBM SPSS software package version 20.0. (Armonk, NY: IBM Corp).

\section{- Mesulian DNMT3a gene expression in group I pre- chemotherapy was 46.5. Group II exhibited markedly lower values with a median of 0.98 with a $P$-value $<0.001$. At the end of treatment, group I cohort had an evident decrease showing a median of 17 .}

DNMT3A gene sequencing by Sanger technique has been done, to identify cases having R882 mutation from those harboring no mutation. 12 patients exhibited a mutation at the hotspot region of the gene (i.e.: $27 \%$ ).

Serum nitrite of group I showed a median $12 \mathrm{Umol} / \mathrm{L}$ performed for group I on day 28 to demonstrate a median level of $6.2 \mathrm{Umol} / \mathrm{L}$ values of 0.035 and 0.001 respectively.

- As all the participants either in group I or II expressed DNMT3a, patients were segregated in accordance with the magnitude of expression of the gene, and hence a ROC curve was plotted so as to define a cutoff value in relation to the mutational status. The cutoff point identified was 46.5 , with a sensitivity of $75 \%$ and a specificity of $60.6 \%$. This subdivided group I into two further subgroups: Group la or low expressors and group lb or high expressors.

- Group la and group lb exhibited similarity as regards their TLC, Hgb, PLT, peripheral blast percentages, and bone marrow blast percentages with $P$-values of $0.419,0.445,0.812,0.928$ and 0.303 respectively. There was neither obvious predilection to any $F A B$ subtype nor specific cytogenetic risk group. Both groups had similar clinical outcomes concerning the response to chemotherapy and OS with P-values of 0.92 and 0.49 respectively.

To investigate the prognostic implication of DNMT3a gene expression on survival, plotting of OS for low and high expressors has been done. It was shown that the median survival of the low expressors was 37.5 days, whilst it was 37 days for high expressors showing that they were almost the same. versus $5.8 \mathrm{Umol} / \mathrm{L}$ for group II. Reassessment was

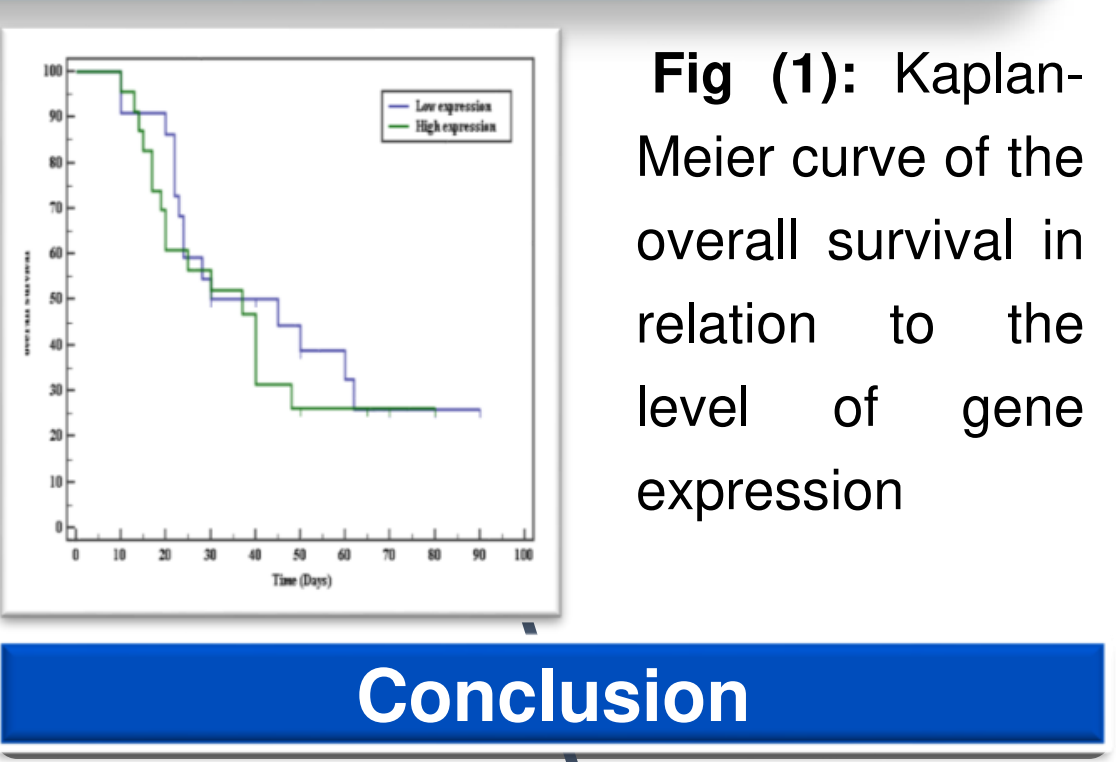

DNMT3a is a universally expressed gene amongst AML patients. Its level of expression does not correlate with any of the laboratory quantitative parameters. Also, it does not predict poorer outcomes or resistance to chemotherapy. AML cohort had higher nitrosative stress than their control group, but this was not of influence in terms of prognosis.

\section{References}

1] Yang $X$ and Wang J: Precision therapy for acute myeloid leukemia. Journal of Hematology and Oncology 2018; 11:3.

2] Kumar DA, Mehta AB, Kumar MP, et al: DNMT3A (R882) mutation features and prognostic effect in acute myeloid leukemia in Coexistent with NPM1 and FLT3
mutations. Hematol Oncol Stem Cell Ther. 2017; xxx: xxx-xxx. 8 Sep 2017, www.sciencedirect.com/science/article/pii/S1 658387617301188

doi.org/10.1016/j.hemonc.2017.09.004 1658-3876, accessed 20 March 2018.

[3] Hou HA, Kuo YY, Liu CY, et al: DNMT3A mutations in acute myeloid leukemia: stability during disease evolution and clinical implications. Blood. 2012; 119: 559-68.

[4] Lu R, Wang P, Parton T, et al: Epigenetic Perturbations by Arg882-Mutated DNMT3A Potentiate Aberrant Stem Cell GeneExpression Program and Acute Leukemia Development. Cancer cell 2016; 30: 92-107.

[5] Choudhari SK, Chaudhary M, Bagde S, et al: Nitric oxide and cancer: a review. World Journal of Surgical Oncology 2013, 11:118. 